\title{
Positive association between the use of quinolones in food animals and the prevalence of fluoroquinolone resistance in E. coli and K. pneumoniae, A. baumanii and $P$. aeruginosa: a global ecological analysis
}

Chris Kenyon ${ }^{1,2 *}$

${ }^{1}$ HIV/STI Unit, Institute of Tropical Medicine, Antwerp, Belgium; 2Division of Infectious Diseases and HIV Medicine, University of Cape Town, Anzio Road, Observatory 7700, South Africa

* Correspondence: author. HIV/STI Unit, Institute of Tropical Medicine, Antwerp, 2000, Belgium. Tel: +32 3 2480796; Fax: +32 3 2480831; E-mail: ckenyon@itg.be

\begin{abstract}
Background: It is unclear what underpins the large global variations in the prevalence of fluoroquinolone resistance in gram-negative bacteria. We tested the hypothesis that different intensities in the use of quinolones for food-animals plays a role. Methods: We used Spearman's correlation to assess if the countrylevel prevalence of fluoroquinolone resistance in human infections with Acinetobacter baumannii, Escherichia coli, Klebsiella pneumoniae and Pseudomonas aeruginosa was correlated with the use of quinolones for food producing animals. Linear regression was used to assess the relative contributions of country-level quinolone consumption for food-animals and humans on fluoroquinolone resistance in these 4 species. Results: The prevalence of fluoroquinolone resistance in each species was positively associated with quinolone use for foodproducing animals $($ E. coli $[\mathrm{\varrho}=0.55 ; \mathrm{P}<0.001]$, K. pneumoniae $[\mathrm{Q}=0.58 ; \mathrm{P}<0.001] ; A$. baumanii $[\mathrm{Q}=0.54 ; \mathrm{P}=0.004] ; P$. aeruginosa $[\mathrm{Q}=0.48 ; \mathrm{P}=0.008])$. Linear regression revealed that both quinolone consumption in humans and food animals were independently associated with fluoroquinolone resistance in E. coli and A. baumanii. Conclusions: Reducing quinolone use in food-producing animals may help retard the spread of fluoroquinolone resistance in various gram negative bacterial species.
\end{abstract}

Keywords: One-health; food-animals; E. coli; K. pneumoniae; Acinetobacter; P. aeruginosa; fluoroquinolones; antimicrobial resistance; antibiotic consumption

\section{Background}

It is unclear why fluoroquinolone resistance in a range of bacterial species emerged so explosively in Asia over the past 20 years [1-4]. Between 1998 and 2009, for example the prevalence of ciprofloxacin resistance in Shigella increased from $0 \%$ to $29 \%$ in Asia compared to $0 \%$ to $0.6 \%$ in Europe-America [1]. Likewise, fluoroquinolone resistance has emerged rapidly in other gram negative bacteria such as Escherichia coli, Pseudomonas spp., and Klebsiella spp. [1-5].

The emergence of fluoroquinolone resistance in various species of Neisseria is particularly instructive. The prevalence of gonococcal ciprofloxacin resistance in China increased from 10\% in 1996 to $95 \%$ in 2003 [6]. By way of contrast the median prevalence of ciprofloxacin resistance in 2009 was $24 \%$ in the Americas and 6\% in Africa [7]. In a 
similar vein, recent studies from China have found that the prevalence of ciprofloxacin resistance to be $100 \%$ in commensal Neisseria and $66 \%$ in $N$. meningitidis [8-10].

There is however considerable heterogeneity in the prevalence of fluoroquinolone resistance within Asia and beyond. The prevalence of fluoroquinolone resistance in $N$. gonorrhoeae and $N$. meningitidis in Australia for example, is considerably lower than that in China [7, 11, 12]. Part of these differences may be explained by differences in fluoroquinolone consumption in humans [7]. Global ecological studies have however found that differences in fluoroquinolone consumption only explain a small proportion in the variation in fluoroquinolone resistance for organisms such as E. coli and $N$. gonorrhoeae [7, 13, 14]. This is also evident if we consider the examples of China and Australia where their not too dissimilar levels of consumption of fluoroquinolones appear to be an implausible explanation for the large differences in the prevalence in fluoroquinolones resistance in gram-negative bacteria (Table 1). A more striking difference between China and Australia shown in Table 1, is the larger quantity of quinolones used for animal husbandry in China.

Quinolone use in food-producing animals has been linked to quinolone resistance in a number of gram-negative pathogens circulating in humans $[15,16]$. This use of quinolones could induce resistance in bacteria circulating in humans both directly or indirectly. Direct selection would occur via human ingestion of quinolone residues in meat or water/soil contaminated by animal manure [17]. Quinolones have been found to show very low biodegradability in the environment $[17,18]$. Selection could also occur indirectly where quinolones select for resistance in bacteria in the food-animals and these bacteria or their resistance determinants are then transferred to humans. This indirect pathway has been shown to be important in the genesis and spread of cephalosporin resistance (mainly via the spread of plasmids) in various gram-negative bacteria such as E. coli [15].

To the best of our knowledge, only one previous ecological analyses has assessed if there is an association between fluoroquinolone use in animal husbandry and fluoroquinolone resistance in human pathogens [19]. This study was limited to European countries and found that fluoroquinolone consumption in food-producing animals was positively associated with fluoroquinolone resistance in human infections with number of gram-negative pathogens including Campylobacter jejuni and Salmonella spp. [19, 20]. Differences in fluoroquinolone use for foodproducing animals are less pronounced between European countries than globaly. We therefore hypothesized that differences in fluoroquinolone consumption in food-producing animals would be positively associated with a greater number of bacterial species than within Europe.

\section{Methods}

Data

Antimicrobial Resistance Data

The country-level prevalence of fluoroquinolone resistance for $A$. baumanii, Escherichia coli, Klebsiella pneumoniae and Pseudomonas aeruginosa was taken from the Center for Disease Dynamics, Economics \& Policy's (CDDEP) ResistanceMap database. CDDEP aggregates data on antibiotic 
resistance from several sources. The data are then harmonized to present similar definitions of resistance across countries and regions to enable comparisons between countries. Further details pertaining to the methodology and definitions used to define antimicrobial resistance can be found at [21]. The list of sources used to obtain the data is provided in STable 1. CDDEP provides data on fluroquinolone resistance for 10 bacterial species but only 4 of these have data for more than 15 countries. We limited our analyses to these 4 species. For each of the species a resistance prevalence estimate from a single year for each country was provided in the dataset. This typically applied to the year 2017.

Quinolone use for food-animal data. We obtained the country level consumption of quinolones for animal food production in the year 2013 from a systematic review on this topic performed by Broeckel et al. [22]. This study calculated the volume of antimicrobials (in tons) by class of antimicrobial in 38 countries in the year 2013. Four categories of animals were included: chicken, cattle, pigs and small ruminants (sheep and goats), which together account for the overwhelming majority of terrestrial animals raised for food [15, 22].

We used this data to calculate the number of milligrams of quinolones used for animal food production/population correction unit (PCU - a kilogram of animal product) in the year 2013. The data for the tonnage of food animals produced per country and year in the year 2013 was taken from the Food and Agriculture Organization estimates (http://www.fao.org/faostat/en/?\#data/).

Human fluoroquinolone consumption data.

Data from IQVIA were used as a measure of national antimicrobial drug consumption in 2015 - the most recent year for which data is available. Details for how IQVIA calculates these consumption estimates is provided in SBox 1 [7].

\section{Statistical Analyses}

For each comparison, Spearman's correlation was used to assess the country-level association between the prevalence of fluoroquinolone resistance in each species and (1) quinolone use for animals and (2) quinolone consumption by humans. Linear regression was used to assess the country-level association between the prevalence of fluoroquinolone resistance in each species and the two independent variables in 3 models. In the first model, we assessed the association between fluoroquinolone resistance and fluoroquinolone consumption in humans (Model-1). In Model-2 we assessed the association between fluoroquinolone resistance and quinolone use in animals. In Model-3 we evaluated the effect of both independent variables on fluoroquinolone resistance.

Sensitivity analysis. China had a considerably higher consumption of quinolones for food-producing animals which meant it was a clear outlier in the dataset and may have skewed the linear regression analyses (Table 1; SFig. 1). In sensitivity analyses we therefore repeated the analyses excluding China. All statistical analyses were performed in Stata 16.0 and a p-value of $<0.05$ was regarded as statistically significant.

\section{Results}


The prevalence of fluoroquinolone resistance varied considerably between countries (E. coli- median 31.5\% [IQR 22.5-47.5]; K. pneumoniaemedian 44\% [IQR 27-62]; A. baumanii- median 53.5\% [IQR 14-82]; $P$. aeruginosa- median $21.5 \%$ [IQR 15-34]; Table 1). Large differences in the consumption of fluoroquinolones were also evident between countries median 721 defined daily doses/1000 inhabitants/year (IQR 421-1129; Table 1).

Quinolone use for food-producing animals varied considerably in the 36 countries with data available (median $1.9 \mathrm{mg}$ quinolones/PCU (IQR 0.7-6.6 mg/PCU; Table 1). Quinolone exposure was highest in China (261.2 mg/PCU).

\section{Spearman's correlations}

The prevalence of fluoroquinolone resistance in each species was positively associated with quinolone use for food-producing animals ( $E$. coli $[\mathrm{Q}=0.55 ; \mathrm{P}<0.001 ; \mathrm{N}=35]$, K. pneumoniae $[\mathrm{Q}=0.58 ; \mathrm{P}<0.001 ; \mathrm{N}=31] ; A$. baumanii $[\mathrm{Q}=0.54 ; \mathrm{P}=0.004 ; \mathrm{N}=26] ; P$. aeruginosa $[\mathrm{Q}=0.48 ; \mathrm{P}=0.008 ; \mathrm{N}=29]$ ) and quinolone consumption in humans (E. coli $[\mathrm{Q}=0.58 ; \mathrm{P}<0.001 ; \mathrm{N}=47], K$. pneumoniae $[\mathrm{Q}=0.42 ; \mathrm{P}=0.006 ; \mathrm{N}=42] ;$ A. baumanii $[\mathrm{Q}=0.54 ; \mathrm{P}<0.001 ; \mathrm{N}=54]$; $P$. aeruginosa $[\mathrm{Q}=0.58 ; \mathrm{P}<0.001 ; \mathrm{N}=37]$; Table 2$)$.

\section{Linear regression models}

For both K. pneumoniae and P. aeuginosa, only human consumption of fluoroquinolones had a statistically significant effect on the prevalence of resistance (Table 3 ). In the case of $E$. coli and A. baumanii, both consumption in humans and food animals were significantly associated with fluoroquinolone resistance (Table 2). In the case of A. baumanii, this association was statistically significant in the multivariate but not the bivariate model. For both species the combined model (Model-3) was a better predictor of fluoroquinolone resistance than Model-2 which only considered human fluoroquinolone consumption (E. coli: $\mathrm{R}^{2}$ increased from 0.27 to 0.48 ; A. baumanii: $\mathrm{R}^{2}$ increased from 0.26 to 0.59 ; Table 2 ).

\section{Sensitivity analyses}

Excluding China from the Pearson's correlations had no effect on the results (STable 2). It did however affect the results of the linear regression analyses. The major change was that the positive association between the prevalence of fluoroquinolone resistance in E. coli and the consumption of quinolones in food-producing animals was no longer statistically significant (STable 3).

\section{Discussion}

In this global ecological study Spearman's correlation revealed that the prevalence of fluoroquinolone resistance in all four species was positively associated with the use of quinolones for food-animals. In the case of $E$. coli and A. baumanii, linear regression analyses suggested that quinolone consumption in both humans and food animals plays a role in the explaining global differences in the prevalence of fluoroquinolone resistance. As far as K. pneumoniae and P. aeruginosa were concerned, this association was statistically significant in the Spearman's correlation but not the linear regression analyses. This difference is likely influenced by one outlier in the data - China. In the dataset, China has a very high consumption of quinolones for food animals, a high prevalence of 
resistance for E. coli, A. baumanii and lower resistance prevalences for $P$. aeruginosa and K. pneumoniae. The results of the sensitivity analysis are compatible with this explanation.

Numerous limitations mean that due caution should be exercised in drawing conclusion from this analysis. These limitations include the relatively small number of countries with available data, the lack of longitudinal data on quinolone consumption in animals and the absence of data on quinolone use for aquaculture. The fluoroquinolone resistance prevalence estimates from CDDEP are based on various methodologies making cross country comparisons problematic. We did not adjust our analyses for either differences in susceptiblity testing strategies or breakpoints between countries or over time as this information is not provided by CDDEP. These limitations should however result in a misclassification bias which would typically result in a bias towards the null hypothesis [23]. The epidemiology of resistance is complex and factors other than the amount of quinolones consumed may influence the level of quinolone resistance. These include poor sanitation, inadequate processing of sewage, substandard regulation of antimicrobials, weak antimicrobial stewardship, consumption of other classes of antimicrobials, travel by humans and trade of live animals and meat, variations in environmental temperatures and high levels of institutional corruption [3-5, 13-15, 24]. We did not control for any of these.

Despite these limitations, various types of evidence suggest that excessive use of antimicrobials in food-producing animals could play a role in inducing AMR in bacteria in humans. In addition to the ecological evidence of a positive association between quinolone consumption for food animals and fluoroquinolone resistance in bacteria in humans from Europeans countries reviewed above [19], other European studies have found positive assocations between the prevalence of fluoroquinolone resistance in E. coli in humans and E. coli from poultry and pigs [20]. A systematic review on the topic found evidence that fluoroquinolone and cephalosporin resistance could be transferred from E. coli in foodproducing animals to humans [16].

As noted above, an alternative pathway for quinolones used in foodanimal production to induce resistance would be via humans ingesting quinolone residues in meat or water/soil contaminated by animal manure [17]. Antimicrobial concentrations up to 230-fold lower than the minimal inhibitory concentration can induce AMR in bacteria such as E. coli and Salmonella enterica spp. $[25,26]$. Concentrations of ciprofloxacin as low as $0.1 \mu \mathrm{g} / \mathrm{L}$ have, for example, been shown to able to select for resistance in certain gram negative bacteria [25, 27]. This is termed the minimum selection concentration (MSC) [25]. Quinolone concentrations in meat, water and environmental samples exceed this threshold by some margin in a number of countries, but especially so in certain Asian countries. For example, studies have found that the mean concentration of ciprofloxacin in samples of milk, eggs, and edible fish in China to be $8.5 \mu \mathrm{g} / \mathrm{L}, 16.8$ $\mu \mathrm{g} / \mathrm{kg}$ and $331.7 \mu \mathrm{g} / \mathrm{kg}$ respectively [28-30]. The ingestion of these relatively high concentrations of quinolones in food products was the favoured explanation for the the high median concentration of quinolones (median $20 \mu \mathrm{g} / \mathrm{kg}$ ), found in the colons of the general human population in 3 regions of China [31]. This concentration is 200 fold higher than the MSC for E. coli [27]. In a similar vein, a study from South Korea found that high urinary excretion of enrofloxacin and ciprofloxacin in the general population were strongly associated with consumption of 
beef, chicken and dairy products [32]. Finally, reducing the consumption of these foodstuffs in South Korea has been shown to result in a reduction of urinary quinolone concentrations [33]. Very low concentrations of antimicrobials such as fluoroquinolones can not only generate de-novo resistance but they can also select for the enrichment of already present resistant mutants [25, 27]. It is thus possible that fluoroquinolone consumption in humans plays a dominant role in the genesis of de-novo resistance and that low concentrations of quinolones consumed in food may promote the spread of these resistant strains.

Ecological studies are best considered hypothesis generating. The results of this study need to be followed up by detailed individual-level, association studies. Randomized controlled trials would be particularly valuable. One study design would be to randomize groups of mice or humans to various schemas of low dose antimicrobials to assess the effect on antimicrobial susceptibilities of their resident bacteria.

Acknowledgments: We would like to thank CDDEP for the data provided.

Authors' contributions. CK conceptualized the study. CK was responsible for the acquisition, analysis and interpretation of data. CK read and approved the final draft.

Consent for publication: Not applicable

Data availability: The data we used is publicly available from: https://resistancemap.cddep.org/AntibioticResistance.php

Funding: No specific funding was received for this work.

Competing interests: None to declare. All the authors declare that they have no conflicts of interest. 
Table 1. Country-level consumption of quinolones for food-producing animals (milligrams of quinolones used for animal food production/PCU), fluoroquinolone consumption in humans (defined daily doses/1000 inhabitants per year) and prevalence of resistance to fluoroquinolones (\%) for 4 bacterial species.

\begin{tabular}{|c|c|c|c|c|c|c|}
\hline Country & $\begin{array}{c}\text { Quinolone Food } \\
\text { Animals }\end{array}$ & $\begin{array}{l}\text { Quinolones } \\
\text { humans }\end{array}$ & K. pneumoniae & E.coli & P.aeruginosa & A.baumanii \\
\hline Argentina & & 648 & 51 & 34 & 25 & 83 \\
\hline Australia & 0 & 245 & 4 & 12 & 5 & 6 \\
\hline Austria & 0.0706 & 699 & 16 & 22 & 12 & 9 \\
\hline Belarus & & & 83 & 48 & 87 & 90 \\
\hline Belgium & 0.2882 & 1246 & 27 & 25 & 12 & 14 \\
\hline Bosnia & & & 56 & & 40 & \\
\hline Bulgaria & 0.3877 & 1178 & 68 & 43 & 32 & 96 \\
\hline Canada & 0.0105 & 815 & 19 & 21 & 19 & . \\
\hline Chile & & 577 & & 29 & & \\
\hline China & 16.0223 & 389 & 42 & 56 & 15 & 82 \\
\hline Croatia & & 733 & 48 & 29 & 38 & 98 \\
\hline Cyprus & 0.1139 & & 45 & 44 & 25 & 76 \\
\hline Czech Republic & 0.1149 & 402 & 54 & 26 & 30 & 20 \\
\hline Denmark & 0.3004 & 292 & & 14 & . & 1 \\
\hline Ecuador & & 733 & 47 & 59 & 22 & 55 \\
\hline Egypt & & 1152 & 80 & & . & . \\
\hline Estonia & 0.1554 & 376 & 30 & 20 & 13 & \\
\hline Finland & 0.0184 & 398 & 15 & 14 & 11 & 3 \\
\hline France & 0.1415 & 688 & 29 & 17 & 17 & 13 \\
\hline Georgia & & . & 68 & . & . & . \\
\hline Germany & 0.1414 & 701 & 18 & 23 & 16 & 9 \\
\hline Ghana & & . & 61 & 59 & 29 & 26 \\
\hline Greece & & 1242 & 69 & 34 & 38 & 96 \\
\hline Hungary & 0.7233 & 1130 & 42 & 31 & 23 & 67 \\
\hline Iceland & 0.0121 & & & 14 & & \\
\hline India & & 762 & 69 & 84 & 34 & 58 \\
\hline Ireland & 0.1945 & 433 & 19 & 26 & 16 & \\
\hline Italy & 0.5165 & 1486 & 58 & 47 & 29 & 79 \\
\hline Japan & 0.0518 & 954 & & 30 & . & . \\
\hline Kenya & & & 40 & 58 & . & . \\
\hline Latvia & 0.1951 & 418 & 35 & 32 & . & . \\
\hline Lebanon & & & & 45 & . & . \\
\hline Lithuania & 0.1657 & 564 & 66 & 28 & 21 & . \\
\hline Luxembourg & 0.1508 & 1064 & 29 & . & 21 & . \\
\hline Malawi & & & 45 & & . & . \\
\hline Malaysia & & 355 & & 26 & . & 50 \\
\hline Mexico & & 434 & 28 & 62 & 23 & 95 \\
\hline Netherlands & 0.1671 & 374 & 16 & 16 & 12 & 3 \\
\hline New Zealand & 0.0088 & 136 & . & 10 & . & . \\
\hline Nigeria & & & 75 & 76 & . & . \\
\hline Norway & 0.1408 & 258 & 13 & 16 & 5 & 0 \\
\hline Oman & & & 42 & 43 & . & . \\
\hline Pakistan & & 1642 & 58 & 59 & . & \\
\hline Philippines & & 262 & 32 & 39 & 18 & 40 \\
\hline Poland & 0.887 & 638 & 68 & 38 & 39 & 83 \\
\hline Portugal & 0.7636 & 876 & 49 & 30 & 25 & 38 \\
\hline Romania & & 1382 & 66 & 28 & 62 & 90 \\
\hline Russia & & 1129 & 87 & 63 & 58 & 94 \\
\hline Saudi Arabia & & . & 40 & 47 & . & . \\
\hline Serbia & & 1158 & 74 & & 53 & \\
\hline Slovakia & 0.1339 & 1088 & 68 & 47 & 47 & 52 \\
\hline Slovenia & 0.1462 & 546 & 34 & 26 & 20 & 50 \\
\hline South Africa & & 589 & ( & 28 & 35 & 66 \\
\hline South Korea & 1.0048 & 766 & & 37 & . & \\
\hline Spain & 1.464 & 1180 & 24 & 33 & 24 & 73 \\
\hline Sri Lanka & 0.1531 & 578 & 49 & 59 & . & 33 \\
\hline Sweden & 0.00418 & 354 & 12 & 17 & 9 & 0 \\
\hline
\end{tabular}




\begin{tabular}{|c|c|c|c|c|c|c|}
\hline Switzerland & 0.05 & 716 & 11 & 19 & 7 & 14 \\
\hline Tajikistan & & & & . & 17 & . \\
\hline Thailand & & 726 & 35 & 47 & 15 & 57 \\
\hline Tunisia & & 851 & 57 & 19 & & \\
\hline Turkey & & 1352 & 62 & 55 & 35 & 92 \\
\hline UAE & & 1280 & 27 & 49 & & . \\
\hline USA & 0.0538 & 1002 & 10 & 31 & 19 & 39 \\
\hline United Kingdom & 0.038 & 251 & 12 & 18 & 10 & 17 \\
\hline Venezuela & & 1199 & 17 & 50 & & 81 \\
\hline Vietnam & 0.1196 & 1162 & 44 & 66 & 21 & 57 \\
\hline Zambia & & & 69 & . & . & . \\
\hline Zimbabwe & & & 44 & . & 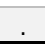 & . \\
\hline
\end{tabular}

Table 2. Spearman's correlation matrix of country-level prevalence of fluoroquinolone resistance (\%) in 4 bacterial species and quinolone consumption in food-producing animals (milligrams of quinolones used for animal food production/PCU) and fluoroquinolone consumption in humans (defined daily doses/1000 inhabitants per year).

\begin{tabular}{|c|c|c|c|c|c|c|}
\hline & $\begin{array}{c}\text { Acinetobacter } \\
\text { baumannii }\end{array}$ & Escherichia coli & $\begin{array}{c}\text { Pseudomonas } \\
\text { aeruginosa }\end{array}$ & $\begin{array}{c}\text { Klebsiella } \\
\text { pneumoniae }\end{array}$ & $\begin{array}{c}\text { Food-animal FQ } \\
\text { consumption }\end{array}$ & $\begin{array}{c}\text { Human FQ } \\
\text { consumption }\end{array}$ \\
\hline $\begin{array}{c}\text { Acinetobacter } \\
\text { baumannii }\end{array}$ & 1 & & & & & \\
\hline Escherichia coli & $0.66^{* *}$ & 1 & & & & \\
\hline $\begin{array}{c}\text { Pseudomonas } \\
\text { aeruginosa }\end{array}$ & $0.76^{\star *}$ & $0.72^{* *}$ & 1 & & & \\
\hline $\begin{array}{c}\text { Klebsiella } \\
\text { pneumoniae }\end{array}$ & $0.72^{\star \star}$ & $0.61^{\star *}$ & $0.90^{\star *}$ & 1 & & \\
\hline $\begin{array}{c}\text { Food-animal FQ } \\
\text { consumption }\end{array}$ & $0.54^{* *}$ & $0.55^{\star *}$ & $0.46^{* *}$ & $0.58^{* *}$ & 1 & \\
\hline $\begin{array}{c}\text { Human FQ } \\
\text { consumption }\end{array}$ & $0.54^{* *}$ & $0.58^{* *}$ & $0.58^{\star *}$ & $0.42^{*}$ & $0.35^{\star}$ & 1 \\
\hline
\end{tabular}


Table 3. Linear regression models testing the country-level association between quinolone consumption in food-producing animals and humans and the prevalence fluoroquinolone resistance in E. coli, K. pneumoniae, A. baumanii and $P$. aeruginosa spp. [coefficients (95\% confidence intervals)]

\begin{tabular}{|c|c|c|c|c|c|c|c|c|c|c|c|c|}
\hline & \multicolumn{3}{|c|}{ E. coli } & \multicolumn{3}{|c|}{ K. pneumoniae } & \multicolumn{3}{|c|}{ A. baumanii } & \multicolumn{3}{|c|}{ P. aeruginosa } \\
\hline & Model 1 & Model 2 & Model 3 & Model 1 & Model 2 & Model 3 & Model 1 & Model 2 & Model 3 & Model 1 & Model 2 & Model 3 \\
\hline $\begin{array}{l}\text { Quinolones } \\
\text { food animals }\end{array}$ & $\begin{array}{l}1.93 \quad(.21- \\
3.65)^{*}\end{array}$ & - & $\begin{array}{l}2.2 \\
3.56)^{\star *}\end{array}$ & $\begin{array}{l}.84(-1.76- \\
3.44)\end{array}$ & - & $\begin{array}{l}1.21(-1.25- \\
3.68)\end{array}$ & $\begin{array}{l}3.62 \quad(-.39- \\
7.64)\end{array}$ & - & $\begin{array}{l}4.6 \quad(1.79- \\
7.46)^{\star *}\end{array}$ & $\begin{array}{l}-.11(-1.42- \\
1.21)\end{array}$ & - & $\begin{array}{l}.14(-1.02- \\
1.30)\end{array}$ \\
\hline $\begin{array}{l}\text { Quinolones } \\
\text { humans }\end{array}$ & - & $\begin{array}{l}.02 \\
(.01-.03)^{* *}\end{array}$ & $\begin{array}{l}.02 \\
(.01-.03)^{* *}\end{array}$ & - & $\begin{array}{l}.02 \\
(.01-.04)^{* *}\end{array}$ & $\begin{array}{l}.02 \\
(.00-.04)^{*}\end{array}$ & - & $\begin{array}{l}.05 \\
(.02-.08)^{* *}\end{array}$ & $\begin{array}{l}.06 \\
(.03-.08)^{\star *}\end{array}$ & - & $\begin{array}{l}.02 \\
(.01-.03)^{\star \star}\end{array}$ & $\begin{array}{l}.01 \\
(.01-.02)^{\star \star}\end{array}$ \\
\hline$N$ & 35 & 47 & 33 & 31 & 42 & 30 & 26 & 35 & 25 & 29 & 37 & 28 \\
\hline $\mathrm{R}^{2}$ & 0.14 & 0.27 & 0.48 & 0.01 & 0.19 & 0.18 & 0.13 & 0.26 & 0.59 & 0.00 & 0.29 & 0.29 \\
\hline
\end{tabular}

${ }^{*}$ P-value $<0.05,{ }^{* *}$ P-value $<0.005$ 


\section{References}

1. Gu B, Cao Y, Pan S, Zhuang L, Yu R, Peng Z, et al. Comparison of the prevalence and changing resistance to nalidixic acid and ciprofloxacin of Shigella between Europe-America and Asia-Africa from 1998 to 2009. Int J Antimicrob Ag. 2012;40(1):9-17.

2. Lu P-L, Liu Y-C, Toh H-S, Lee Y-L, Liu Y-M, Ho C-M, et al. Epidemiology and antimicrobial susceptibility profiles of Gram-negative bacteria causing urinary tract infections in the Asia-Pacific region: 2009-2010 results from the Study for Monitoring Antimicrobial Resistance Trends (SMART). Int J Antimicrob Ag. 2012;40:S37-S43.

3. Song J. Antimicrobial resistance control in Asia. AMR control. 2015:41-5.

4. Yam ELY, Hsu LY, Yap EP, Yeo TW, Lee V, Schlundt J, et al. Antimicrobial Resistance in the Asia Pacific region: a meeting report. Antimicrob Resist Infect Control. 2019;8:202. Epub 2020/01/01. doi: 10.1186/s13756019-0654-8. PubMed PMID: 31890158; PubMed Central PMCID: PMCPMC6921568.

5. Chereau F, Opatowski L, Tourdjman M, Vong S. Risk assessment for antibiotic resistance in South East Asia. Bmj. 2017;358.

6. Bash MC, McKnew DL, Tapsall JW. Antibiotic Resistance in Neisseria. Antimicrobial Drug Resistance: Springer; 2009. p. 763-82.

7. Kenyon C, Buyze J, Wi T. Antimicrobial consumption and susceptibility of Neisseria gonorrhoeae: a global ecological analysis. Frontiers in medicine. 2018;5:329.

8. Chen M, Zhang C, Zhang X, Chen M. Meningococcal quinolone resistance originated from several commensal Neisseria species. Antimicrobial agents and chemotherapy. 2019.

9. Shen YF, Chen ML. Prevalence, sequence type, and quinolone resistance of Neisseria lactamica carried in children younger than 15 years in Shanghai, China. Journal of Infection. 2020;80(1):61-8. doi: 10.1016/j.jinf.2019.08.020. PubMed PMID: WOS:000507459600008.

10. Yang Y, Liao MM, Gu WM, Bell K, Wu L, Eng NF, et al. Antimicrobial susceptibility and molecular determinants of quinolone resistance in Neisseria gonorrhoeae isolates from Shanghai. J Antimicrob Chemoth. 2006;58(4):868-72. doi: 10.1093/jac/dkl301. PubMed PMID: WOS:000240587400028.

11. Australian Commission on Safety Quality in Health Care. Preliminary Report on Antimicrobial Use and Resistance in Australia (AURA). ACSQHC Sydney, Australia; 2014.

12. Wi T, Lahra MM, Ndowa F, Bala M, Dillon JR, Ramon-Pardo P, et al. Antimicrobial resistance in Neisseria gonorrhoeae: Global surveillance and a call for international collaborative action. PLoS Med. 2017;14(7):e1002344. Epub 2017/07/08. doi: 10.1371/journal.pmed.1002344. PubMed PMID: 28686231; PubMed Central PMCID: PMCPMC5501266.

13. Collignon P, Beggs JJ, Walsh TR, Gandra S, Laxminarayan R. Anthropological and socioeconomic factors contributing to global antimicrobial resistance: a univariate and multivariable analysis. The Lancet Planetary Health. 2018;2(9):e398-e405.

14. Collignon P, Athukorala P-c, Senanayake S, Khan F. Antimicrobial resistance: the major contribution of poor governance and corruption to this growing problem. PloS one. 2015;10(3):e0116746.

15. Authority EFS. The European Union Summary Report on Antimicrobial Resistance in zoonotic and indicator bacteria from humans, animals and food in 2018/2019. Efsa J. 2021;19(4).

16. Muloi D, Ward MJ, Pedersen AB, Fevre EM, Woolhouse ME, van Bunnik BA. Are food animals responsible for transfer of antimicrobial-resistant Escherichia coli or their resistance determinants to human populations? A systematic review. Foodborne pathogens and disease. 2018;15(8):467-74.

17. Ben Y, Fu C, Hu M, Liu L, Wong MH, Zheng C. Human health risk assessment of antibiotic resistance associated with antibiotic residues in the environment: A review. Environ Res. 2019;169:483-93. Epub 2018/12/12. doi: 10.1016/j.envres.2018.11.040. PubMed PMID: 30530088.

18. Cantas L, Shah SQ, Cavaco LM, Manaia CM, Walsh F, Popowska M, et al. A brief multi-disciplinary review on antimicrobial resistance in medicine and its linkage to the global environmental microbiota. Front Microbiol. 2013;4:96. Epub 2013/05/16. doi: 10.3389/fmicb.2013.00096. PubMed PMID: 23675371; PubMed Central PMCID: PMCPMC3653125.

19. ECDC/EFSA/EMA. ECDC/EFSA/EMA second joint report on the integrated analysis of the consumption of antimicrobial agents and occurrence of antimicrobial resistance in bacteria from humans and food-producing animals: Joint Interagency Antimicrobial Consumption and Resistance Analysis (JIACRA) Report. Efsa J. 2017;15(7). doi: UNSP 4872

10.2903/j.efsa.2017.4872. PubMed PMID: WOS:000406685200007.

20. Vieira AR, Collignon P, Aarestrup FM, McEwen SA, Hendriksen RS, Hald T, et al. Association between antimicrobial resistance in Escherichia coli isolates from food animals and blood stream isolates from humans in Europe: an ecological study. Foodborne pathogens and disease. 2011;8(12):1295-301.

21. The Center for Disease Dynamics Economics \& Policy. ResistanceMap: Antibiotic resistance. 2021 [cited 2021]. Available from: 2021. https://resistancemap.cddep.org/AntibioticResistance.php. 
22. Van Boeckel TP, Glennon EE, Chen D, Gilbert M, Robinson TP, Grenfell BT, et al. Reducing antimicrobial use in food animals. Science. 2017;357(6358):1350-2.

23. Chyou P-H. Patterns of bias due to differential misclassification by case-control status in a case-control study. European journal of epidemiology. 2007;22(1):7.

24. Lundborg CS, Tamhankar AJ. Antibiotic residues in the environment of South East Asia. Bmj. 2017;358.

25. Gullberg E, Albrecht LM, Karlsson C, Sandegren L, Andersson DI. Selection of a multidrug resistance plasmid by sublethal levels of antibiotics and heavy metals. MBio. 2014;5(5).

26. Stanton IC, Murray AK, Zhang L, Snape J, Gaze WH. Evolution of antibiotic resistance at low antibiotic concentrations including selection below the minimal selective concentration. Communications biology. 2020;3(1):1-11.

27. Gullberg E, Cao S, Berg OG, Ilbäck C, Sandegren L, Hughes D, et al. Selection of resistant bacteria at very low antibiotic concentrations. PLoS Pathog. 2011;7(7):e1002158.

28. Yang Y, Qiu W, Li Y, Liu L. Antibiotic residues in poultry food in Fujian Province of China. Food Addit Contam Part B Surveill. 2020;13(3):177-84. Epub 2020/04/21. doi: 10.1080/19393210.2020.1751309. PubMed PMID: 32308157.

29. Huang L, Mo Y, Wu Z, Rad S, Song X, Zeng H, et al. Occurrence, distribution, and health risk assessment of quinolone antibiotics in water, sediment, and fish species of Qingshitan reservoir, South China. Sci Rep. 2020;10(1):15777. Epub 2020/09/27. doi: 10.1038/s41598-020-72324-9. PubMed PMID: 32978412; PubMed Central PMCID: PMCPMC7519050.

30. Zheng N, Wang J, Han R, Xu X, Zhen Y, Qu X, et al. Occurrence of several main antibiotic residues in raw milk in 10 provinces of China. Food Additives \& Contaminants: Part B. 2013;6(2):84-9.

31. Wang Q, Duan YJ, Wang SP, Wang LT, Hou ZL, Cui YX, et al. Occurrence and distribution of clinical and veterinary antibiotics in the faeces of a Chinese population. J Hazard Mater. 2020;383:121129. Epub 2019/09/24. doi: 10.1016/j.jhazmat.2019.121129. PubMed PMID: 31546217.

32. Ji K, Kho Y, Park C, Paek D, Ryu P, Paek D, et al. Influence of water and food consumption on inadvertent antibiotics intake among general population. Environmental research. 2010;110(7):641-9.

33. Ji K, Kho YL, Park Y, Choi K. Influence of a five-day vegetarian diet on urinary levels of antibiotics and phthalate metabolites: a pilot study with "Temple Stay" participants. Environmental research. 2010;110(4):375-82. 